\title{
Professor Suresh Prasad Mandal: A Tribute
}

\section{Dr Narayan Chetry ${ }^{\dagger}$}

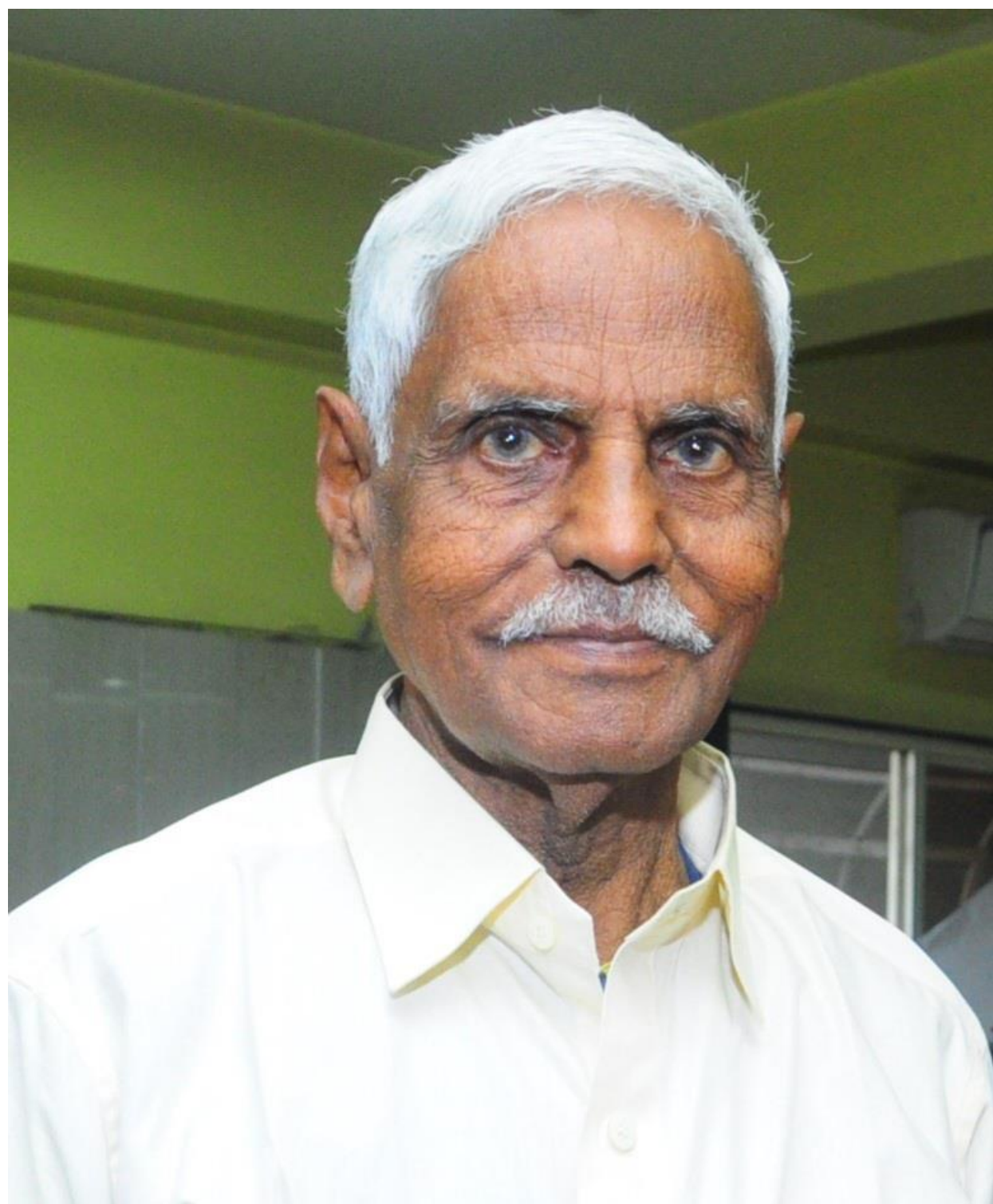

Born on 1 January 1939 at Bhagalpur Bihar, family and leaving aside Bihar Administrative Professor Suresh Prasad Mandal needs no Service, he chose teaching and learning as deep introduction among Geography fraternity in passion and profession. He was quite adapted to Assam (India). He was the founder teacher of language, culture and food habits of Assam Geography Department, Darrang College, although these were quite different from his Tezpur (Assam), a premier college in the north native place. Right from 1960 to 1997, he served bank of the river Brahmaputra. Professor Darrang College, Tezpur in various capacitiesMandal passed his Masters in Geography in 1959 as a founder Head of the Department, Vicefrom Patna University. Hailing from a farmer's Principal and Principal in charge. He was an

\footnotetext{
${ }^{\dagger}$ Associate Professor (Retired), Cotton University, Guwahati, Assam, India, Email: narayan.chetry@yahoo.in (C) 2020 Chetry. This is an Open Access article distributed under the terms of the Creative Commons Attribution License (http://creativecommons.org/licenses/by/2.0), which permits unrestricted use, distribution, and reproduction in any medium, provided the original work is properly cited.
} 
actual Karmayogi, a dedicated mentor and a real teacher. He devoted for dedicated teaching during his entire service life from 8:30 AM to 7:30 PM on the college campus.

We always found him with books, and he kept himself busy in preparing class notes for the students. He updated the teaching materials always with new sources of information. He developed departmental infrastructure, including a dynamic departmental library with a large number of valuable books. The departmental library not only supported the need of the undergraduate students in the college but also the books of this library were utilised to cater the needs of Post Graduate students in various universities, where his students were enrolled for Master's programme. His personal library was endowed with valuable books too, and these were open to any students and the newly appointed teachers. He used to care the pass out undergraduate students who enrolled in Gauhati University when he used to visit them in the hostel and stayed with them. He always took care of the educational need of the students by motivating, mentoring and tutoring them in groups. There were no vacations and leaves for him; the students assembled at his classes. He also addressed the financial needs of the poor students. He was a friend, philosopher and guide of every student.

He used to pay a large bill for tea and snacks served to students during his extra class and supervision of practical works of the students. Besides, he used to conduct regular examination for honours students to check their progress in studies. Indeed, he helped many students to realise their dreams. His constant support for books and reading materials from the personal library to many students and teachers, helped them to build their academic career and confidence in mind. He encouraged and inspired every student. Some of his students, who attained prominent positions are: Late Dulal Chandra Bhuyan, Deputy Director Town and Country Planning, Assam; Shri Hemanta Bijay Mahanta, Principal Commissioner of Income Tax, Government of India; Dr Ashok Kumar Bora,
Professor, Geography, Gauhati University; Dr Bimal Kar, Professor, Geography, Gauhati University; Dr Narayan Chetry, Associate Professor(retired), Cotton University, Guwahati; Dr Bimal Barah, Principal, J B College, Jorhat; Dr Jay Sankar Hazarika, Principal Darrang College, Tezpur; Dr. Bhupen Saikia, Principal (retd), Dr Birinchi Kumar Barooah College, Purani Gudam, Nagaon Assam. In addition, many of his students teach in various colleges and schools of Assam and North East India

A teacher like Mandal Sir is rarely found in the current climate. He has shown the way what precisely a teacher is meant for. His sheer dedication in shaping the career of the students debarred him from translating his teachings into publications. Indeed, he was a man who lived for others.

During his tenure as the Head of Geography Department (1960- 1997), Vice Principal and Principal in Charge of Darrang College, Tezpur, the Department of Geography alongside the college made significant progress in producing brilliant performances of the students. His dream of developing the department of Geography into a Post Graduate study was recognised recently. This recognition is definitely because of the infrastructure he developed during his tenure.

He left for heavenly abode on 14 October 2020 leaving a great void among his family members, friends and a large number of followers and students. His wife Professor Manorama Mandal Baidew predeceased him. He is survived by his two children-both of them are doctors-Dr Bharati Puspam Mandal and Dr Dipam Puspam Mandal

We, the students of several batches, the teachers of the college and the department assembled during the most challenging time of COVID-19 pandemic by maintaining its protocol to pay our homage to this great teacher and shared our fond memories on 24 October 2020 at Darrang College, Tezpur. May his eternal soul Rest in Peace. 